\title{
Toward Resilience: Medical Students' Perception of Social Support
}

Sharon Casapulla, MEd, EdD, MPH; Jason Rodriguez, MEd, OMS IV; Samantha Nandyal, OMS II; Bhakti Chavan, MBBS, MPH

From the Office of Rural and Underserved Programs (Dr Casapulla) and the Office of Research and Grants (Ms Chavran) at Heritage College of Osteopathic Medicine at Ohio University in Athens (Student Drs Rodriguez and Nandyal) Financial Disclosures: None reported.

Support: None reported.

Address correspondence to Sharon Casapulla, MEd, EdD, MPH, 47 Oxbow Trail, 126 Irvine Hall, Heritage College of Osteopathic Medicine, Ohio University, Athens, OH, 45701-6809.

Email: casapull@ohio.edu

Submitted August 16, 2019; revision received February 18, 2020; accepted March 30, 2020.
Context: There is strong evidence that social support — particularly perceived social supportfunctions as a protective factor for health. Few studies have investigated how medical students perceive the types of social support they experience.

Objective: To determine how osteopathic medical students perceive social support, understand the factors that influence their perceptions, and explore how group participation in a cocurricular, academic program could affect student perceptions.

Methods: In this cross-sectional study of 983 medical students at a multicampus osteopathic medical school in the Midwest, potential respondents were invited by email in March 2018 to participate in a self-reported evaluation of their perceived social support using a 40-question Interpersonal Support Evaluation List (ISEL). The demographic variables included gender, race, age, current phase in medical school, Hispanic heritage, campus assignment, and hometown population type. A total score for each type of social support and a summative score for overall perceived social support were calculated. Descriptive statistics were applied to provide a summary of the distribution of study variables. Bivariate analyses were conducted using student $t$ test and analysis of variance (ANOVA) statistic to determine distribution of 4 social support constructs and overall social support by all the study variables; $\alpha<.05$ was considered statistically significant. Linear regression analysis was performed to determine the association between all study variables and 4 social support constructs. Pairwise interactions were calculated to determine whether the association differed by any of the study variables.

Results: Self-esteem support was the lowest type of perceived social support overall in the total sample (mean [SD], 23.5[2.0]). Hispanic students reported lower overall mean perceived social support than those who did not identify as Hispanic (100 vs $104 ; P=.04$ ). Older study participants had higher mean tangible support compared with their younger counterparts (26.25 vs. 25.60, $P=.018 ; t[264]=1.18$ ). Older study participants also had higher mean appraisal support compared with their younger counterparts (26.57 vs. $25.92, P=.06 ; t[266]=1.27$ ). Female medical students reported lower levels of belonging support overall (mean [SD] $26.79,[2.10])$. Students from rural hometowns reported a higher sense of belonging support than any other group. Female students from suburban and urban hometowns reported lower levels of belonging support compared with women from rural hometowns (Adj. $\beta=-0.96$, $P=.01$ ). Students who participated in the rural and urban underserved program had higher self esteem support compared with those who did not participate in the rural and urban underserved program (Adj. $\beta=-1.30, P=.05$ ). Students in the clinical phase of medical education reported lower levels of belonging support than students in the preclinical phase (26.14 vs. 26.69, $P=.05 ; \mathrm{t}[256]=1.07)$.

Conclusions: It is critical to understand the ways medical students experience social support and the factors that contribute to it. Longitudinal studies following medical students over time would contribute to a more complete understanding of social support in medical students as they move from preclinical to the clinical phases of medical school.

J Am Osteopath Assoc. 2020;120(12):844-854. Published online November 9, 2020. doi:10.7556/jaoa.2020.158

Keywords: medical students, resilience, social support, stress 
$\mathrm{S}$

tress among medical students has been a concern of educators for decades. ${ }^{1-6}$ Despite this concern, medical students are still experiencing higher levels of stress, depression, anxiety, and overall psychological distress than the general population. ${ }^{7-9}$ One study ${ }^{10}$ found that depression in medical students worsens over time, suggesting that emotional distress for medical students is "chronic and persistent rather than episodic." Two studies ${ }^{9,10}$ have reported a gender difference, finding that female medical students had higher levels of stress and depression; another study ${ }^{11}$ of medical students in Norway found no gender difference related to depression or stress and attributed this to the "equal position of genders in Norway." Increasingly, medical schools are implementing programs designed to build resilience in medical students, ${ }^{12-18}$ and resilience has become a focus of medical education. ${ }^{19}$ Yet, research into protective factors, specifically in the medical school curriculum, has been limited. ${ }^{20,21}$

Resilience has been defined in many different ways and contexts. In the field of psychology, where research in resilient individuals started decades ago, ${ }^{22,23}$ resilience has been defined as the ability to recover and thrive in the face of adversity. ${ }^{24-26}$ Antonovsky, ${ }^{27}$ a medical sociologist, described resilient individuals as those who manage stress well and find meaning in situations that could be considered "overwhelming psychological threats."13 Resilience has been theorized to exist within individuals, families, communities, and institutions. ${ }^{19,24}$ Indeed, resilience acts across all levels of the ecological model. ${ }^{28}$ A resilient community may function as a protective factor for resilience at the individual level. ${ }^{13}$ For example, at the individual level, resilience involves a connection to the social environment. $^{29}$ A community or social environment can support or impair a person's ability to build resilience. $^{30}$ These findings suggest that resilience can be developed or learned. ${ }^{6}$

Howe et $\mathrm{al}^{13}$ studied resilience in medical students and described the components of resilience as selfefficacy, self-control, ability to engage support systems (social support), learning from difficulties, and persistence. Generally, social support is considered to be a function of social relationships, ${ }^{31}$ and it can be both positive and negative. Researchers have proposed 4 types of social support: emotional support involving empathy, love, trust and caring; instrumental/tangible support involving tangible aid and services that assist a person in need; informational support which involves advice, suggestions, and information that a person can use to address problems; and appraisal support involves constructive feedback and affirmation. $^{32}$ The Interpersonal Support Evaluation List $(\text { ISEL) })^{33}$ is a validated scale that applies a variation of this framework.

There is strong evidence that social supportparticularly perceived social support-functions as a protective factor for health. ${ }^{34-36}$ In the context of medical education, research has found a strong association between group membership and well-being. ${ }^{37} \mathrm{~A}$ study ${ }^{38}$ of 849 male and 1149 female Chinese medical students with ages ranging from 18 to 26 years found a strong negative relationship between mental health problems and social support (response rate, 96.57\%). Female medical students had lower overall resilience scores than their male counterparts. In a study of 127 Australian medical students, ${ }^{39}$ social support was found to negatively correlate with student burnout. In a study $^{6}$ of 161 medical students in North Dakota, the authors found that medical students with lower levels of perceived social support had greater odds of moderate or severe depression and were more likely to experience high levels of emotional exhaustion and low sense of personal accomplishment. The authors concluded that it was "imperative" 6 to develop programs in medical schools that promote social support.

In this exploratory study, we aimed to determine how osteopathic medical students perceive the 4 types of social support, which factors influence their perceptions of social support (including participation on organizations and activities, and whether differences were evident between preclinical vs clinical years or different demographic groups. 


\section{Methods}

This study used a nonexperimental design with a convenience sample of medical students from a single osteopathic medical school in the Midwest ( $n=983$ ). The medical student sample consisted of 3 separate campuses with approximately 572, 203, and 208 students, respectively. All medical students enrolled at all locations were invited to participate in an online survey via an email invitation. The survey was open from March 24, 2018 to April 15, 2018. The email contained a link to a Qualtrics survey, which included a consent form to which the participant indicated agreement using a checkbox. Participation was voluntary and respondents were entered in a raffle to win a $\$ 50$ gift card. Two email reminders were sent at week 2 and week 3 to all enrolled students during the data collection period. The study was approved by the institutional review board (IRB\# $18 \times 79$ ).

\section{Instruments}

We asked several demographic questions including gender (female, male, transgender female, transgender male, gender variant/nonconforming, other), race (American Indian, Asian, Black or African American, Native Hawaiian or Other Pacific Islander, White or Caucasian), age (text input box), current phase in medical school (preclinical or clinical), Hispanic heritage (yes or no), campus assignment, and whether the student would characterize their hometown as rural, urban, or suburban.

We used the validated ISEL scale, ${ }^{33}$ which includes a series of survey questions to which participants indicated agreement using a Likert-like scale, with 0 indicating definitely false and 3 indicating definitely true. The ISEL consists of a list of 40 statements concerning the perceived availability of potential social resources. The ISEL measures 4 separate functions of social support and overall support; these are closely aligned with the 4 types of social support described earlier. The items which comprise the ISEL fall into 4 10-item subscales: the tangible subscale measures perceived availability of material aid; the appraisal subscale mea- sures the perceived availability of someone to talk to about one's problems; the self-esteem subscale measures the perceived availability of a positive comparison when comparing oneself with others; and the belonging subscale measures the perceived availability of people one can do things with.

\section{Study Variables}

The main study variables were overall social support, which was calculated as a sum of the 40 items on the ISEL as well as a sum score of each of the 4 subscales. The study included several covariates like age (21-24 years, $\geq 25$ years), race (nonHispanic White, nonHispanic Black, Hispanic, Asian, Other), hometown (rural, urban, suburban), year in school (preclinical, clinical), campus (Athens, Dublin, Cleveland) and participation in the Rural and Urban Scholars Pathway (RUSP) program.

\section{Data Analysis}

A total score for each type of social support and a summative score for overall perceived social support were calculated.

Data were first evaluated for assumptions (eg, normality, homogeneity of variances, etc.), checked for outliers, and assessed for systematic bias to ensure valid analyses. Transformations were applied as necessary. Descriptive statistics were applied to provide a summary of the distribution of study variables. The corresponding mean, standard deviation (SD), frequencies and percentages were reported. Bivariate analyses were conducted using independent sample $t$ test and analysis of variance (ANOVA) statistic to determine distribution of the 4 social support constructs and overall social support by all the study variables; $\alpha<.05$ was considered statistically significant. Linear regression analysis was performed to determine the association between all the study variables and the 4 social support constructs. Pairwise interactions were calculated to determine whether the association differed by any of the study variables. The corresponding coefficient, 95\% confidence 
interval $(95 \% \mathrm{CI})$, and $P$ value were reported. Potential multicollinearity was assessed using tolerance and variance inflation factor (VIF). The regression analysis was not prone to multicollinearity. All analyses were conducted in SAS University Edition, version 9.04 (SAS Institute).

\section{Results}

Of the 983 students surveyed, 316 consented to participate and 290 responded to the full survey (response rate, 29.5\%). The study demographics included 177 participants who were 25 years of age or older (61.0\%), 158 women (54.7\%), 235 who identified as nonHispanic White $(81.3 \%)$, and 187 who were in the preclinical year $(66.6 \%)$, defined as first or second year of medical school. Many participants $(173 ; 59 \%)$ were from suburban hometowns; 94 (32.1\%) were from rural hometowns and $26(8.9 \%)$ were from urban hometowns, while 148 attended the rural campus (51.7\%), and 37 participated in the RUSP (18.4\%). The demographic profile of the respondents was representative of the student body at the time of the survey (Table 1), including the percentage of students on each of the 3 campuses.

\section{Race and Ethnicity}

$T$ tests and ANOVAs were calculated for all study variables (Table 2). Only 1 demographic variable resulted in differences in overall perceived social support. The mean overall social support score for those respondents who identified as Hispanic ( $\mathrm{n}=9)$ was significantly lower (mean, 100; $P=.04$, equal variances not assumed) than those who did not identify as Hispanic ( $\mathrm{n}=289$; mean, 104), with a moderate effects size (Cohen $d=.81$ ). There were no other differences in overall social support by any of the study variables. Further analysis revealed that self-esteem support (mean self-esteem support, 23.71) was the type of

\section{Table 1.}

Characteristics of the Study Population $(\mathrm{N}=290)^{a}$

\begin{tabular}{lr}
\hline Characteristics & No. (\%) \\
\hline $21-24$ & $113(39.0)$ \\
\hline$\geq 25$ & $177(61.0)$ \\
\hline Gender & $131(45.3)$ \\
\hline Male & $158(54.7)$ \\
\hline Female & \\
\hline Race & $235(81.3)$ \\
\hline NonHispanic White & $19(6.6)$ \\
\hline NonHispanic Black & $28(9.7)$ \\
\hline Asian & $9(3.1)$ \\
\hline Hispanic & $7(2.4)$ \\
\hline Other & \\
\hline Hometown & $94(32.1)$ \\
\hline Rural & $173(59.0)$ \\
\hline Suburban & $26(8.9)$ \\
\hline Urban
\end{tabular}

\begin{tabular}{lr}
\hline \multicolumn{1}{l}{ Year in school } & \\
\hline Preclinical (OMS I and II) & $187(66.6)$ \\
\hline Clinical (OMS III and IV) & $94(33.4)$ \\
\hline Campus & $148(51.0)$ \\
\hline A (Rural/small town) & $100(34.5)$ \\
\hline B (Suburban) & $42(14.5)$ \\
\hline C (Urban) & $37(18.4)$ \\
\hline RUSP participation & $164(81.6)$ \\
\hline Yes & $26.22(2.14)$ \\
\hline No & $26.48(2.10)$ \\
\hline Appraisal support, mean (SD) & $23.50(2.00)$ \\
\hline Belonging support, mean (SD) & $25.75(1.89)$ \\
\hline Self-esteem support, mean (SD)
\end{tabular}

a Data given as No. (\%) unless otherwise noted.

Abbreviations: OMS, osteopathic medical student; RUSP, Rural and Urban Scholars Pathway program 
Table 2.

Characteristics of the Study Population by the 4 Social Support Constructs

\begin{tabular}{|c|c|c|c|c|c|c|c|c|}
\hline \multirow[b]{2}{*}{ Characteristics } & \multicolumn{2}{|c|}{ Appraisal support } & \multicolumn{2}{|c|}{ Belonging support } & \multicolumn{2}{|c|}{ Self-esteem support } & \multicolumn{2}{|c|}{ Tangible support } \\
\hline & Mean (SD) & $P$ value & Mean (SD) & $P$ value & Mean (SD) & $P$ value & Mean (SD) & $P$ value \\
\hline Age & & .101 & & .126 & & .238 & & .186 \\
\hline $21-24$ & $25.95(2.27)$ & & $26.72(1.98)$ & & $23.32(2.14)$ & & $25.56(1.79)$ & \\
\hline$\geq 25$ & $26.39(2.01)$ & & $26.31(2.17)$ & & $23.62(1.92)$ & & $25.88(1.94)$ & \\
\hline Gender & & .314 & & $.033^{\mathrm{a}}$ & & .921 & & .538 \\
\hline Male & $26.37(2.14)$ & & $26.79(2.10)$ & & $23.52(1.90)$ & & $25.69(2.03)$ & \\
\hline Female & $26.10(2.16)$ & & $26.23(2.08)$ & & $23.50(2.09)$ & & $25.83(1.77)$ & \\
\hline Race & & $0.155^{\mathrm{b}}$ & & $0.941^{b}$ & & $0.803^{b}$ & & $0.955^{\mathrm{b}}$ \\
\hline NonHispanic White & $26.34(2.08)$ & & $26.46(2.13)$ & & $23.51(1.94)$ & & $25.78(1.92)$ & \\
\hline NonHispanic Black & $25.21(2.53)$ & & $26.47(1.22)$ & & $23.53(2.14)$ & & $25.95(1.54)$ & \\
\hline Hispanic & $25.78(2.28)$ & & $26.56(1.33)$ & & $21.44(1.67)$ & & $24.56(1.74)$ & \\
\hline Asian & $26.04(2.31)$ & & $26.54(2.48)$ & & $23.48(2.50)$ & & $25.70(1.99)$ & \\
\hline Other & $25.83(1.94)$ & & $27.00(1.90)$ & & $24.33(1.86)$ & & $25.50(0.84)$ & \\
\hline Hometown & & $.061^{\mathrm{b}}$ & & $.069^{b}$ & & $.786^{\mathrm{b}}$ & & $.354^{\mathrm{b}}$ \\
\hline Rural & $26.11(2.41)$ & & $26.77(2.08)$ & & $23.48(2.03)$ & & $25.94(1.96)$ & \\
\hline Suburban & $26.41(1.98)$ & & $26.44(2.01)$ & & $23.55(2.02)$ & & $25.62(1.79)$ & \\
\hline Urban & $25.33(1.93)$ & & $25.67(2.55)$ & & $23.25(1.82)$ & & $26.00(2.25)$ & \\
\hline Year in school & & .376 & & $.053^{\mathrm{a}}$ & & .172 & & .964 \\
\hline Preclinical (OMS I and II) & $26.17(2.26)$ & & $26.69(2.14)$ & & $23.40(2.11)$ & & $25.82(1.94)$ & \\
\hline Clinical (OMS III and IV) & $26.42(1.96)$ & & $26.14(2.07)$ & & $23.77(1.86)$ & & $25.80(1.71)$ & \\
\hline Campus & & $.536^{\mathrm{b}}$ & & $.298^{\mathrm{b}}$ & & $.660^{\mathrm{b}}$ & & $.114^{\mathrm{b}}$ \\
\hline Rural & $26.35(2.09)$ & & $26.51(2.10)$ & & $23.46(2.04)$ & & $25.53(1.84)$ & \\
\hline Suburban & $26.02(2.15)$ & & $26.27(2.23)$ & & $23.63(1.96)$ & & $26.07(1.81)$ & \\
\hline Urban & $26.23(2.33)$ & & $26.90(1.79)$ & & $23.29(2.01)$ & & $25.74(2.16)$ & \\
\hline RUSP participation & & .939 & & .833 & & .213 & & .182 \\
\hline Yes & $26.22(1.93)$ & & $26.59(2.17)$ & & $23.24(2.03)$ & & $26.27(1.84)$ & \\
\hline No & $26.25(2.24)$ & & $26.52(2.00)$ & & $23.72(2.08)$ & & $25.82(1.84)$ & \\
\hline
\end{tabular}

$P$ value $<.05$

b Analysis of variance test statistic ' $F$ ' value

Abbreviations: OMS, osteopathic medical student; RUSP, Rural and Urban Scholars Pathway program; SD, Standard deviation.

social support with the lowest score and was driving the low overall score for Hispanic students. The mean selfesteem support was lowest among Hispanic students (mean, 21.44)

\section{Gender}

Table 3 shows stratified analysis results by gender. Mean belonging support was highest among male students from rural hometowns, followed by male students 
Table 3.

Association Between Study Population Characteristics and Social Support Constructs by Gender ${ }^{a}$

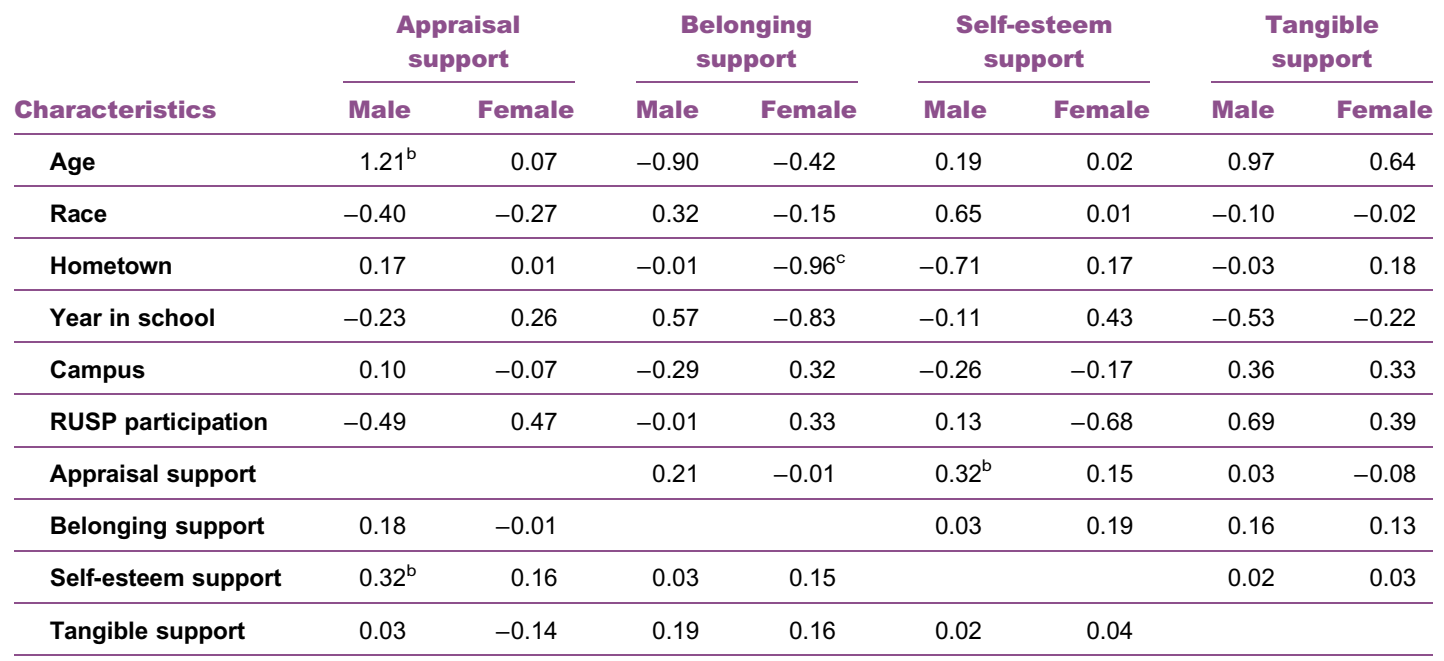

a Data presented as adjusted $\beta$.

b $P$ value $<.05$

c $P$ value $<.01$

Abbreviation: RUSP, Rural and Urban Scholars Pathway program

from suburban hometowns, and lowest among male students from urban home towns (means, 26.44 suburban vs 26.77 rural vs 25.57 urban; $P=.03$; 1-way ANOVA, $\mathrm{F}[2267]=2.70)$. There was a significant association between age, self-esteem support, and appraisal support among all men after adjusting for all the potential confounders $(P=.05)$. Older male participants (25 years of age or older) had higher appraisal support compared with their younger male counterparts (21-24 years of age; Adj. $\beta=1.21, P=.043)$. Similarly, there was a significant positive association between all men's appraisal support and self-esteem support (Adj. $\beta=0.32, P=.01$ ), indicating that as self-esteem support increased, the appraisal support also increased.

There was a significant association between hometown and belonging support among women, after adjusting for all the potential confounders. Belonging support was lower among female students from suburban $(n=88)$ and urban hometowns $(n=14)$ compared with female students from rural hometowns $(n=56$;
Adj. $\beta=-0.96, P=.01)$. Among women, there was no significant association between self-esteem support or appraisal support and any of the study variables. There was no significant association between tangible support and any of the study variables when analyzed by gender.

\section{Age}

Bivariate analysis revealed a significant association between age, RUSP participation, and tangible support. Older study participants had higher mean tangible support compared with their younger counterparts (26.25 vs. $25.60, P=.018 ; t[264]=1.18$ ).

\section{Group Participation}

Among students from suburban hometowns $(n=173)$, there was a significant negative association between RUSP participation and self-esteem support, after adjusting for all the potential confounders. Students who did not belong to the RUSP ( $n=37$ ) had lower 


\section{Table 4.}

Association Between Study Population Characteristics and Social Support Constructs by Year in School ${ }^{\mathbf{a}}$

\begin{tabular}{|c|c|c|c|c|c|c|c|c|}
\hline \multirow[b]{2}{*}{ Characteristics } & \multicolumn{2}{|c|}{ Appraisal support } & \multicolumn{2}{|c|}{ Belonging support } & \multicolumn{2}{|c|}{ Self-esteem support } & \multicolumn{2}{|c|}{ Tangible support } \\
\hline & Preclinical & Clinical & Preclinical & Clinical & Preclinical & Clinical & Preclinical & Clinical \\
\hline Age & 0.50 & 1.92 & -0.60 & -0.54 & 0.31 & -1.51 & 0.69 & 1.56 \\
\hline Gender & 0.22 & 0.40 & 0.21 & 0.94 & -0.02 & -0.12 & -0.05 & 0.01 \\
\hline Race & -0.25 & -0.26 & 0.02 & 0.01 & 0.23 & 0.16 & -0.21 & 0.29 \\
\hline Hometown & -0.23 & 0.63 & -0.43 & -0.96 & -0.36 & 0.41 & 0.02 & 0.26 \\
\hline Campus & -0.21 & 0.75 & -0.09 & 0.50 & -0.22 & -0.12 & 0.39 & 0.40 \\
\hline RUSP participation & 0.44 & -0.92 & -0.19 & 0.95 & -0.57 & -0.38 & 0.15 & 1.04 \\
\hline Appraisal support & & & 0.03 & 0.13 & $0.25^{\mathrm{b}}$ & 0.06 & -0.03 & -0.06 \\
\hline Belonging support & 0.03 & 0.18 & & & 0.11 & 0.15 & 0.13 & 0.14 \\
\hline Self-esteem support & $0.26^{b}$ & 0.06 & 0.11 & 0.12 & & & 0.02 & 0.07 \\
\hline Tangible support & -0.04 & -0.13 & 0.15 & 0.23 & 0.02 & 0.15 & & \\
\hline
\end{tabular}

a Data presented as adjusted $\beta$.

b $P<.01$

Abbreviation: RUSP, Rural and Urban Scholars Pathway program.

self-esteem support compared with RUSP participants (Adj. $\beta=-1.30, P=.05$ ). No other group participation resulted in significant differences.

\section{Year in School}

Table 4 represents the stratified analysis results by year in school. Students in the clinical phase of medical education (OMS III and OMS IV) reported lower levels of belonging support than students in the preclinical phase (26.14 vs. $26.69, P=.053 ; t[256]=1.07$ ). There was a significant positive association among preclinical students $(n=187)$ between appraisal support and selfesteem support, after adjusting for all the potential confounders (Adj. $\beta=0.26, P=.01$ ). As self-esteem support increased, appraisal support increased and vice versa. Among clinical students $(n=94)$, there was no significant association between appraisal support and any of the study variables. There was no significant association between belonging support and any of the study variables when stratified by year in school. There was no significant association between tangible support and any of the study variables when stratified by year in school.

\section{Rural, Suburban, and Urban Hometown}

Mean appraisal support was highest among students from suburban hometowns (26.58), followed by rural hometowns (26.14), and lowest among students from urban hometowns $(25.33 ; P=.051 ; 1$-way ANOVA $[\mathrm{F}(2267)=2.83]$; Table 5). The stratified analysis results by hometown are represented in Table 5. Among students from rural and urban hometowns, there was a significant positive association between self-esteem support and appraisal support, after adjusting for all the potential confounders (rural hometown: Adj. $\beta=0.42$, $P=.04$; urban hometown: Adj. $\beta=0.77, P=.03$ ). As selfesteem support increased, appraisal support increased. Among students from suburban hometowns, there was no significant association between appraisal support and any of the study variables. There was no significant association between belonging support and any of the study variables when stratified by hometown. 
There was a significant association between hometown and belonging support among women, after adjusting for all the potential confounders. Belonging support was lower among female students from suburban $(n=88)$ and urban hometowns $(n=14)$ compared with female students from rural hometowns $(n=56$; Adj. $\beta=-0.96, P=.01$ ). There was no significant association among men between belonging support and any of the study variables.

Among all students from rural hometowns, there was a significant association between age, appraisal support and self-esteem support, after adjusting for all the potential confounders. Older study participants from rural hometowns $(\mathrm{n}=53)$ had lower self-esteem support compared with their younger counterparts ( $n=40$; Adj. $\beta=-1.26, P=.03$ ). Similarly, there was a significant positive association between appraisal support and self-esteem support (Adj. $\beta=0.22, P=.04$ ) indicating that as appraisal support increased, self-esteem support increased.

Among students from urban hometowns $(n=26)$, there was a significant positive association between appraisal support and self-esteem support, after adjusting for all the potential confounders (Adj. $\beta=0.47$, $P=.03$ ) indicating that as appraisal support increased, self-esteem support increased. Among students from suburban hometowns $(n=173)$, there was a significant positive association between age and tangible support, after adjusting for all the potential confounders (Adj. $\beta=1.10, P=.01$ ) indicating that older study participants $(n=177)$ had higher tangible support compared with their younger counterparts $(n=113)$. Among students from rural and urban hometowns, there was no significant association between tangible support and any of the study variables.

\section{Discussion}

Consistent with recommendations to understand social support as a multidimensional construct, we did not categorize students into those with "high" or "low" perceived social support. However, we did find that students who identified as Hispanic reported lower overall social support. Self-esteem support, which measures the perceived availability of a positive comparison when comparing oneself with others, was the lowest perceived social support overall in the total sample. However, this type of social support did not differ by any of the study variables.

Belonging support refers to the perceived availability of social peers; female medical students reported lower levels of belonging support overall. Other studies ${ }^{9,10}$ have found that female medical students have higher levels of depression and stress. Resilience research in physicians has shown that cultivating relationships with colleagues protects against burnout. ${ }^{41,42}$

Students from rural hometowns reported a higher sense of belonging support than any other group. Students' hometowns appear to play a role in their perceptions of social support; students from suburban hometowns who participated in RUSP also reported higher self-esteem support. Students who participated in RUSP reported higher perceived belonging and tangible support than students who dit not. Students in the clinical phase of medical education (OMS III and OMS IV) reported lower levels of belonging support than students in the preclinical phase, suggesting that programs should be in place to support students as they move away from their academic campuses and into the clinical setting.

Overall, many factors affect perceptions of social support, and we found associations between the 4 constructs of social support in some groups, which suggests that the constructs are not discrete but are interrelated. This study brings to light some potential implications for practice. Medical schools should examine the levels of social support experienced in their students. The findings from this study suggest a need to increase belonging support in female students and students in the clinical phases of medical education. Overall, self-esteem support was the type of social support with the lowest mean in all groups for all variables; follow-up qualitative studies are needed to identify what aspects of medical education 


\section{Table 5.}

Association Between Study Population Characteristics and Social Support Constructs by Hometown Type ${ }^{a}$

\begin{tabular}{|c|c|c|c|c|c|c|c|c|c|c|c|c|}
\hline & \multicolumn{3}{|c|}{ Appraisal support } & \multicolumn{3}{|c|}{ Belonging support } & \multicolumn{3}{|c|}{ Self-esteem support } & \multicolumn{3}{|c|}{ Tangible support } \\
\hline & Rural & Suburban & Urban & Rural & Suburban & Urban & Rural & Suburban & Urban & Rural & Suburban & Urban \\
\hline Age & 0.87 & 0.47 & 0.03 & -0.55 & -0.59 & -0.21 & $-1.26^{b}$ & 1.15 & 0.99 & 0.49 & $1.10^{\mathrm{b}}$ & 1.65 \\
\hline Gender & 0.24 & 0.28 & -0.35 & -0.01 & 0.29 & 2.25 & 0.42 & -0.29 & 0.20 & 0.09 & 0.12 & -0.24 \\
\hline Race & -0.03 & -0.36 & -0.55 & -0.21 & 0.16 & -0.80 & -0.21 & 0.21 & 0.68 & -0.05 & -0.01 & -0.11 \\
\hline Year in school & -0.86 & 0.58 & -0.36 & -0.05 & -0.26 & -1.58 & 0.50 & -0.14 & 0.25 & -0.54 & -0.33 & -1.80 \\
\hline Campus & -0.04 & -0.33 & -0.25 & -0.24 & 0.12 & 1.48 & 0.21 & -0.27 & 0.21 & -0.13 & 0.50 & 1.62 \\
\hline $\begin{array}{l}\text { RUSP } \\
\text { participation }\end{array}$ & -0.11 & 0.13 & -0.50 & 0.06 & 0.15 & -0.06 & -0.19 & $-1.30^{b}$ & 1.47 & 0.28 & 0.35 & 0.34 \\
\hline $\begin{array}{l}\text { Appraisal } \\
\text { support }\end{array}$ & & & & 0.01 & 0.03 & 0.40 & $0.22^{\mathrm{b}}$ & 0.11 & $0.47^{b}$ & -0.15 & 0.03 & 0.03 \\
\hline $\begin{array}{l}\text { Belonging } \\
\text { support }\end{array}$ & 0.01 & 0.03 & 0.20 & & & & 0.18 & 0.18 & -0.11 & 0.17 & 0.17 & -0.06 \\
\hline $\begin{array}{l}\text { Self-esteem } \\
\text { support }\end{array}$ & $0.42^{b}$ & 0.09 & $0.77^{b}$ & 0.21 & 0.14 & -0.35 & & & & 0.19 & -0.07 & 0.04 \\
\hline $\begin{array}{l}\text { Tangible } \\
\text { support }\end{array}$ & -0.25 & 0.04 & 0.02 & 0.17 & 0.24 & -0.08 & 0.17 & -0.13 & 0.02 & & & \\
\hline
\end{tabular}

a Data presented as adjusted $\beta$.

b $P<.05$

Abbreviation: RUSP, Rural and Urban Scholars Pathway program.

can improve overall self-esteem support for medical students.

Our study was limited by the cross-sectional design and the sample size. Additionally, selection bias was a possible limitation because we used a convenience sample. Some of the grouping variables (eg, participation in specific student organizations) had only a few participants, and therefore, we could not accurately determine results for those variables. Increasing participation in the survey would provide more power and, therefore, more significance in the results. Furthermore, we used a convenience sample, and selection bias should also be considered a limitation. Longitudinal studies following medical students over time would contribute to a more complete understanding of social support in medical students as they move from preclinical to the clinical phases of medical school. Future multi-institutional studies would increase the power of results.

Research has shown that osteopathic physicians contribute proportionally more to rural healthcare than their allopathic colleagues, ${ }^{43}$ and as such, it is important to identify the role that social support plays in overall physician well-being and resilience. One cross-sectional study ${ }^{43}$ of osteopathic otolaryngology residents found that while osteopathic residents reported lower levels of burnout than their allopathic peers, low sense of personal accomplishment and depersonalization were the main factors for burnout of osteopathic residents. Because of the importance of resilience in maintaining health care access in rural areas, increasing social support to osteopathic medical students, residents, and practicing physicians is crucial. 


\section{Conclusion}

Osteopathic medicine focuses on the patient in relation to physical, psychological, spiritual, and social aspects of health. Schools of medicine can model the importance of social support to health by developing programs that promote social support for osteopathic physicians-in-training. If it is imperative to develop programs in medical schools that promote social support, then it is equally critical to first understand how medical students experience social support and the factors that contribute to it. The aim of our study was to explore how osteopathic medical students perceive the 4 types of social support, understand the factors that influence their perceptions, and explore how group participation in an academic program could affect student perceptions of social support. Similar to studies about physician burnout and as suggested by some social support researchers, our findings reinforce the value of understanding social support as a multidimensional construct and the importance of studying social support via measurement of its subtypes (or categories). This more discrete level of understanding can guide medical schools in customizing interventions to address specific areas of need and targeting groups that may need additional social support.

\section{Author Contributions}

All authors provided substantial contributions to conception and design, acquisition of data, or analysis and interpretation of data; all authors drafted the article or revised it critically for important intellectual content; all authors gave final approval of the version of the article to be published; and all authors agree to be accountable for all aspects of the work in ensuring that questions related to the accuracy or integrity of any part of the work are appropriately investigated and resolved.

\section{References}

1. Huebner LA, Royer JA, Moore J. The assessment and remediation of dysfunctional stress in medical school. J Med Educ. 1981;56 (7):547-558. doi:10.1097/00001888-198107000-00002

2. Bjorksten $\mathrm{O}$, Sutherland $\mathrm{S}$, Miller $\mathrm{C}$, Stewart T. Identification of medical student problems and comparison with those of other students. J Med Educ. 1983;58(10):759-767. doi:10.1097/00001888-198310000-00001
3. Michie S, Sandhu S. Stress management for clinical medical students. Med Educ. 1994;28(6):528-533. doi:10.1111/j.1365-2923.1994. tb02731.x

4. Medical students' well-being. Med Educ. 1994;28(1):1-2. doi:10.1111/ j.1365-2923.1994.tb02676.x

5. Wolf TM. Stress, coping and health: enhancing well-being during medical school. Med Educ. 1994;28(1):8-17. doi:10.1111/ j.1365-2923.1994.tb02679.x

6. Thompson G, McBride RB, Hosford CC, Halaas G. Resilience among medical students: The role of coping style and social support. Teach Learn Med. 2016;28(2):174-182. doi:10.1080/10401334.2016.1146611

7. Dyrbye LN, Thomas MR, Shanafelt TD. Systematic review of depression, anxiety, and other indicators of psychological distress among U.S. and Canadian medical students. Acad Med J Assoc Am Med Coll. 2006;81(4):354-373. doi:10.1097। 00001888-200604000-00009

8. Compton MT, Carrera J, Frank E. Stress and depressive symptoms/ dysphoria among US medical students: Results from a large, nationally representative survey. J Nerv Ment Dis. 2008;196(12):891. doi:10.1097/NMD.0b013e3181924d03

9. Dahlin M, Joneborg N, Runeson B. Stress and depression among medical students: a cross-sectional study. Med Educ. 2005;39 (6):594-604. doi:10.1111/j.1365-2929.2005.02176.x

10. Rosal MC, Ockene IS, Ockene JK, Barrett SV, Ma Y, Hebert JR. A longitudinal study of students' depression at one medical school. Acad Med J Assoc Am Med Coll. 1997;72(6):542-546. doi:10.1097/ 00001888-199706000-00022

11. Kjeldstadli $K$, Tyssen $R$, Finset $A$, et al. Life satisfaction and resilience in medical school - a six-year longitudinal, nationwide and comparative study. BMC Med Educ. 2006;6:48. doi:10.1186/1472-6920-6-48

12. Tempski $P$, Martins MA, Paro HB. Teaching and learning resilience: a new agenda in medical education. Med Educ. 2012;46(4):345-346. doi:10.1111/j.1365-2923.2011.04207.x

13. Howe A, Smajdor A, Stöckl A. Towards an understanding of resilience and its relevance to medical training. Med Educ. 2012;46(4):349-356. doi:10.1111/j.1365-2923.2011.04188.x

14. West CP, Dyrbye LN, Erwin PJ, Shanafelt TD. Interventions to prevent and reduce physician burnout: a systematic review and meta-analysis. Lancet. 2016;388(10057):2272-2281. doi:10.1016/S0140-6736(16) 31279-X

15. Finkelstein C, Brownstein A, Scott C, Lan YL. Anxiety and stress reduction in medical education: an intervention. Med Educ. 2007;41 (3):258-264. doi:10.1111/j.1365-2929.2007.02685.x

16. Warnecke E, Quinn S, Ogden K, Towle N, Nelson M. A randomised controlled trial of the effects of mindfulness practice on medical student stress levels. Med Educ. 2011;45(4):381-8. doi:10.1111/ j.1365-2923.2010.03877.x

17. Rosenzweig S, Reibel DK, Greeson JM, Brainard GC, Hojat M Mindfulness-based stress reduction lowers psychological distress in medical students. Teach Learn Med. 2003;15(2):88-92. doi:10.1207/ S15328015TLM1502_03

18. Moir F, Henning M, Hassed C, Moyes SA, Elley CR. A peer-support and mindfulness program to improve the mental health of medical students. Teach Learn Med. 2016;28(3):293-302. doi:10.1080/ 10401334.2016.1153475 
19. Epstein RM, Krasner MS. Physician resilience: what it means, why it matters, and how to promote it. Acad Med J Assoc Am Med Coll. 2013;88(3):301-303. doi:10.1097/ACM.0b013e318280cff0

20. Bore M, Kelly B, Nair B. Potential predictors of psychological distress and well-being in medical students: a cross-sectional pilot study. Adv Med Educ Pract. 2016;7:125-135. doi:10.2147/AMEP.S96802

21. Dyrbye LN, Thomas MR, Shanafelt TD. Medical student distress: causes, consequences, and proposed solutions. Mayo Clin Proc. 2005;80(12):1613-1622. doi:10.4065/80.12.1613.

22. Masten AS, Best KM, Garmezy N. Resilience and development contributions from the study of children who overcome adversity. Dev Psychopathol. 1990;2(04):425-444. doi:10.1017/ S0954579400005812

23. Garmezy N. Children in poverty: resilience despite risk. Psychiatry. 1993;56(1):127-136. doi:10.1080/00332747.1993.11024627

24. Masten AS, Powell JL. A Resilience Framework for Research, Policy, and Practice. In: Luthar SS, ed. Resilience and Vulnerability: Adaptation in the Context of Childhood Adversities. Cambridge: Cambridge University Press; 2003:1-26. doi:10.1017/ CBO9780511615788.003

25. Evans C, Hardaker G. Understandings and applications of resilience. J Multicult Educ. 2015; 9(3). doi:10.1108/JME-06-2015-0020

26. Finn GM, Hafferty FW. Medical student resilience, educational context and incandescent fairy tales. Med Educ. 2014;48(4):342-344. doi:10.1111/medu. 12415

27. Antonovsky A. Unraveling the Mystery of Health: How People Manage Stress and Stay Well. San Francisco, CA, US: Jossey-Bass; 1987.

28. Ungar M. Social ecological complexity and resilience processes. Behav Brain Sci. 2015;38:e124. doi:10.1017/S0140525X14001721

29. Denz-Penhey H, Murdoch C. Personal resiliency: serious diagnosis and prognosis with unexpected quality outcomes. Qual Health Res. 2008;18(3):391-404. doi:10.1177/1049732307313431

30. McAllister M, McKinnon J. The importance of teaching and learning resilience in the health disciplines: a critical review of the literature. Nurse Educ Today. 2009;29(4):371-379. doi:10.1016/j.nedt.2008.10.011

31. Berkman LF, Glass T, Brissette I, Seeman TE. From social integration to health: Durkheim in the new millennium. Soc Sci Med. 2000;51 (6):843-857. doi:10.1016/s0277-9536(00)00065-4

32. House JS, Landis KR, Umberson D. Social relationships and health. Science. 1988;241(4865):540-545. doi:10.1126/science.3399889
33. Cohen S, Hoberman HM. Positive events and social supports as buffers of life change stress. J Appl Soc Psychol. 1983;13(2):99-125.

34. Reblin M, Uchino BN. Social and emotional support and its implication for health: Curr Opin Psychiatry. 2008;21(2):201-205. doi:10.1097। YCO.0b013e3282f3ad89

35. Uchino BN. Social support and health: a review of physiological processes potentially underlying links to disease outcomes. J Behav Med. 2006;29(4):377-387. doi:10.1007/s10865-006-9056-5

36. Tittman SM, Harteau C, Beyer KM. The effects of geographic isolation and social support on the health of wisconsin women. WMJ. 2016;115 (2):65-69.

37. McNeill KG, Kerr A, Mavor KI. Identity and norms: the role of group membership in medical student wellbeing. Perspect Med Educ. 2014;3 (2):101-112. doi:10.1007/s40037-013-0102-z

38. Peng L, Zhang J, Li M, et al. Negative life events and mental health of Chinese medical students: The effect of resilience, personality and social support. Psychiatry Res. 2012;196(1):138-141. doi:10.1016/j. psychres.2011.12.006

39. Bore M, Kelly B, Nair B. Potential predictors of psychological distress and well-being in medical students: a cross-sectional pilot study. Adv Med Educ Pract. 2016. 2;7:125-35. doi:10.2147/ AMEP.S96802

40. Cohen S, Mermelstein R, Kamarck T, Hoberman HM. Measuring the Functional Components of Social Support. In: Sarason IG, Sarason BR, eds. Social Support: Theory, Research and Applications. NATO ASI Series. Dordrecht: Springer Netherlands; 1985:73-94.

41. O'Dowd E, O'Connor P, Lydon S, et al. Stress, coping, and psychological resilience among physicians. BMC Health Serv Res. 2018;18(1):730. doi:10.1186/s12913-018-3541-8

42. Jensen PM, Trollope-Kumar K, Waters H, Everson J. Building physician resilience. Can Fam Physician. 2008;54(5):722-729.

43. MacQueen IT, Maggard-Gibbons M., Capra G. et al. Recruiting rural healthcare providers today: A systematic review of training program success and determinants of geographic choices. J Gen Intern Med. 2018;33, 191-199. doi:10.1007/s11606-017-4210-z.

44. Yost M, Johnson J, Johns M, Burchett K. Burnout among osteopathic otolaryngology residents: Identification during formative training years. J Am Osteopath Assoc. 2014;114(8): 632-641. doi:10.7556/ jaoa.2014.128

(c) 2020 American Osteopathic Association 